\title{
Adult Children and Eldercare: The Moral Considerations of Filial Obligations
}

\author{
Heleana Theixos* \\ University of Miami \\ *Please address correspondence to Heleana Theixos, University of Miami, \\ Department of Philosophy, 1252 Memorial Drive, Ashe Building, Room \\ 721, Coral Gables, FL 33124-4670. Email: h.theixos@ umiami.edu.

\begin{abstract}
This essay investigates the demands on adult children to provide care for their elderly/ill parents from a socio-moral perspective. In order to narrow the examination, the question pursued here is agent-relative: What social and moral complexities are involved for the adult child when their parent(s) need care? First, this article examines our society's expectation that adult children are morally obligated to provide care for their parents. Second, the essay articulates how transgressing against this normative expectation can inure significant moral criticism. The final sections present these tensions within the context of disability.
\end{abstract}

Keywords: eldercare, filial obligations, filial duty, caregiver, abuse, moral trauma

\begin{abstract}
Beyond our evaluative practices (medical evaluations) and our practical reasoning (financial constraints, familial ties, logistics) are countless other constraints and assumptions about what is demanded, what is supererogatory, and what is harmful, in the discussion of elder care. The aims of this essay are less about articulating the grounds of filial duty, and more about exploring some of the latent moral pressures facing adult children who are asked to be involved, in some capacity, in care-giving for their parent(s). This is a perspective piece, from the point of view of moral theory, on the social expectation of filial obligation as it intersects with societal norms. This paper does not advance a position, but instead articulates some of the underlying moral considerations in eldercare.

This essay has three sections: First, a discussion of the pressures all adult children face when deciding how involved they ought to be in their elderly/needy parent's care. Here, I incorporate legal and social literature that recognizes filial obligations, with a brief reflection on academic counterarguments. Secondly, I articulate some of the moral tensions the adult child experiences in relation to these social and legal pressures. I include a discussion of how the adult child faces potential moral exclusion if she/he decides not to care for her/his parent. In the third section, I address the unique aspects of filial care in families with abuse
\end{abstract}


histories, and how there may be no clearly best choice. Ultimately, I conclude that moral tensions, combined with potential social exclusion and criticisms, are disabling to the agent in particularly nuanced ways that are relevant to a discussion about families, disabilities, and the complexities of filial obligations.

\section{Conceptual Discussion of the Obligation to Provide Care}

Distinguishing between the terms caregiving and caring, J. Pepin notes, "Caregiving has been conceptualized mainly as an activity or set of tasks, while caring has been conceptualized mainly as commitment, respect and protection toward the cared for, as well as an activity," (Pepin, 1992, p. 130). Here I will use filial care as an umbrella-term to mean caring for/caregiving (as a contrast to care about) to refer to a host of actions and intentions aimed at bettering the welfare of the parent.

There is an identifiable, measurable expectation in our society that children have obligations to their parents (Aneshensel, Pearlin, Mullan, Zarit, and Whitlatch, 2011); it is not a strict duty with clear parameters, but more of a normative expectation grounded in conceptions of natural connection and concern, reciprocity, empathy, and parental respect. The presumption that children have an obligation to care for their parents is existential; by virtue of the relational designation "offspring," society expects some level of filial care. Admittedly, the force of such an obligation is difficult to articulate, since factors such as the parent's specific needs, desires, and history may mitigate it (see Finch and Mason, 1990), but the content of the obligation is verbally explicit, legally supported, and socially reinforced. There are also distinct culturally-specific pressures (in my own experience, Pakistani, Indian, Chinese, and Greek families have explicit codes of filial care). While I generalize about American culture rather than cultural specifics, we notice these filial expectations across religious and cultural inheritances (Forssén, Carlstedt, and Mortberg, 2005).

Cultural and societal expectations of these kinds are also codified in US legal statutes. At present, filial care laws generally take the form of civil statutes, though 12 states have gone as far as imposing criminal penalties (Rickles-Jordan, 2007). As of this writing, 30 states have filial care laws that establish a legal obligation upon adult children to provide some sort of care for indigent and/or elderly parents. Such laws require that financially-able adult children provide necessary food, clothing, shelter, or medical attendance for their elderly parents, if they are unable to provide for themselves. Historically, these laws date back to Britain's Poor Relief Act of 1601. Today, failure to abide by these social expectations can result in punishment. Filial-care legislation can issue fines, but criminal penalties have rarely been enforced. However, in the current climate of increasing eldercare costs and an aging citizenry, enforcement could certainly increase.

Legal recognition of filial care obligations reflects American society's value investment in family solidarity and mutual aid (Finley et al, 1988, Phillips, 1995, AARP International, 2008), an investment that presupposes the social benefits of such obligations (Marcoen, 2005). In this way, filial care decisions are 
not made wholly privately, as they intersect with members of the broader healthcare culture, members of the family and community, and perhaps with social workers and law enforcement.

\section{Conceptual Discussion of Moral Theory, Filial Duty, and Common Morality} Common morality, the system of everyday rules that we use in our judgments about what one ought to do, bears upon members of society and the relationships they value (Gert, 2004). While moral theorists have largely argued that there is no debt, per se, which children owe to their parents (Daniels, 1982; English, 1992), common morality perceives filial obligations as moral requirements (Zhan, 2005; Forssén, Carlstedt, \& Mortberg, 2005; AARP International, 2008). In the US, while there are differences in culture, religion, and community mores, there is a cross-cultural expectation that children are morally obligated, to some degree, to provide care for their aging parents (Williamson \& Schulz, 1990; Guberman, Maheu, \& Maille, 1992; Wuest et al., 2007).

The social phenomenon that filial obligation has a moral component aligns with our collective morality narrative: the "good" child takes care of her/his parent, the "bad" child does not. Consider, for example, the son who refuses to care for his needy, sick mother, and the cousin who is aghast at his behavior. Such criticisms are of a moral kind: the son is failing to be a good son, and every adult child who decides not to provide care makes himself eligible for moral scrutiny (Opie, 1994; Hodgetts, Pullman, \& Goto, 2003). Because our community locates respect and care for our parents as a "central part of the moral standard," (Callahan, 1985, p. 33), not providing care is considered a moral failing. ${ }^{1}$

The possibility, if not the probability, of social and moral censure for failing to care is phenomenal, manifested in social exclusion, strained familial relations, and a host of other familial/social stresses including criticism, disparagement, mistrust, and censure (see Bauman, 2005, p. 107-115; Opie, 1994; Wuest, 1998; Ryvicker, 2009). This research concerns agents who have transgressed moral norms, whose moral standing is diminished in the eyes of others, and are considered by their community (and often, by themselves) as morally other. To damage our moral standing in our community is significant, such that I (and other moral theorists like Paul Bloomfield) consider moral exclusion disabling. This is because, for most of us, there are compelling selfinterested reasons to conform to socially accepted moral norms, and transgressing norms can be deeply problematic for us psychologically, as well as prudentially (Bloomfield 2008; Opotow, 1990; see also the moral philosophy of Julia Annas, 1995). To be excluded or censured on the grounds that one has failed, morally, is

\footnotetext{
${ }^{1}$ Let me clearly acknowledge that common morality is wrong, for various reasons. The moral community is necessarily under-informed; they hold under-examined (and potentially false) beliefs about the optimum health of the parent, and under-examined (and, according to philosophers, false) beliefs about what the child owes her parent. Yet, while the expectation of a duty to care is impoverished, it is salient, weighty, and impactful, such that the adult child likely feels strong sympathies, if not outright agreement, with her moral community.
} 
significant: moral criticism by one's family, friends, and society has been connected to cases of self harm, illness, substance abuse, domestic abuse, career struggles, and other indices of social and personal failure (Hendin and Haas, 1984; Young, 1996; Block Lewis, 2002; Maguen et al., 2010).

The literature on moral othering and moral censure often refers to it in disability terms, observing that social censure elicits a moral trauma, wherein the agent's moral standing and worth are criticized in such a way that the agent is considered less-moral than the norm. These considerations are not often articulated in filial care discussions, and I think this is a mistake. Our societal conception of filial obligations is intimately connected with how we perceive our moral worth, and thus has important connections to discussions about family, social standing, and disability. Moral exclusion is an experience not often discussed in mainstream healthcare ethics, but it should be. This is because, in practice, it constitutes one of the many areas in which the work of moral philosophers, disability theorists, and healthcare practitioners overlap. Certainly, one could argue that the moral community, for example the critical cousin, are misguided in their moral censure, but what is salient is that, whether the cousin is right or wrong, the responses is reasonable within our social context. If the reader is interested in delving further into the area of moral trauma, good work is being done in the area of military ethics and soldier psychology (see Nancy Sherman's body of work, Sherman 2007; Sherman 2011).

\section{Re-Traumatization and the Adult Child of Abuse}

Adult children of abuse report that, they, too, feel the pressures of common morality, which urge them to care for elderly parents in spite of their abusive histories. This is because we are both sensitive to, but also insensitive to, such histories. While studies in this area are few, it is apparent that common morality expects some degree of filial care even in families with past abuse (Wuest, 1998; Guberman, Maheu, \& Maille, 1992; Baines, 2006). Because common morality, which includes the family, society, and the adult children themselves (Baines, 2006), expects filial duties regardless of past abuse, the topic of moral trauma constitutes another important area of discussion. Children of abuse are especially challenged with self-worth, extreme self-criticism, and viewing themselves as bad (Scott \& Eliav, 2005). Childhood abuse can make it difficult for the adult child to fully realize her own morality, and the potentiality for moral othering may be a kind of re-traumatization perhaps evocative of abusive patterns (Scott \& Eliav, 2005; Kendall-Tackett, 2005). For a discussion of retraumatization I look to Nguyen (2011), but research and opinion are mixed about what constitutes traumatization (Ali Jackson, 2007).

Paradoxically, adult children of abuse have special reasons not to provide care for their abusers (reasons grounded in lack of fellow-feeling, lack of reciprocity), but also special reasons to provide care (grounded in common morality's moral expectations). This situation reflects a complexity of expectations, both psychological and social. Reasons for the adult child not to provide care include considerations for the well-being of both caregiver and 
parent. In families where there is a history of strained relations, caregivers report that providing care has a significantly negative impact on their own well-being (Guberman et al., 1993), with detrimental outcomes like emotional stress, anxiety, and psychosocial disorders (Wuest, 1998). Negative health outcomes for both caregivers and parents are especially prevalent in caregiving relationships with abusive histories (Wuest, Hodgins, Malcolm, Merritt-Gray, \& Seaman, 2007).

In the field of eldercare, there is a concern that, due to issues of retribution, revenge, frustration, and modeling of inter-generational abuse, adult children of abusive histories are "more likely to abuse their parents if they provide care for them" (Ali Jackson, 2007, p. 292). At the most basic level, caregiving without strong fellow-feeling can be deeply problematic for both the caregiver and the care-receiver (Guberman, Maheu, \& Maillé, 1992; Noddings, 2003; Duke Filonowicz, 2008), as studies citing these problems seem just as prevalent as studies noting the benefits.

Reasons for the adult child to provide care include avoiding the kinds of moral criticism and censure she would expect from family, friends, and the community. Some theorists have articulated that caregiving presents an opportunity to transform abuse history and shift family relationships. Indeed, the desire to make connections with family members stood out as a motivational factor explaining why some chose to be caregivers (Phillips, 1995; Goren, 2007). In any case, the adult child of abuse faces a complex dilemma: a community will likely criticize the adult child who does not provide care, in ways perhaps evocative of past abuse patterns; choosing to provide care risks re-exposing oneself to old or new traumas. Therefore, the adult child of abuse is located in a special and nuanced area of tension, in which there is likely no "best choice." What is, I hope, very clear, is that moral censure and moral othering is significant to the point that it can be psychologically and emotionally disabling, and this is a consideration worth understanding.

\section{Conclusion}

In this essay I have aimed to articulate filial obligations as they are located in our own, and in our society's, conception of ourselves as "good children." Inquiring into the best options for our parents' health is a varied and complex task, but this is, of course, not surprising; families are complex, our communities are complex. As the elderly population grows, and as healthcare resources are stretched, the expectation is that family members, primarily adult children, will provide care. The current work of bio-ethicists, healthcare practitioners, legislators, and social theorists guides us toward best practices in eldercare, and it is my hope that the impact - psychologically, emotionally, and morally — on the caregiver will be integral in these decisions. The temptation is to address only the pragmatics, economics, and logistics of eldercare, and to minimize the social and the psychological aspects. However, given our lives' moral complexities, these latter aspects require equal consideration in any discussion of families, filial care, and the socially disabling practice of moral othering. It is appropriate to discuss moral 
othering within the context of disability, especially when we recognize the deep emotional strain that moral criticism can exert upon agents.

Feminist researchers are better equipped to address the particular scope and force of normative pressures on women in more nuanced ways than I have provided here. Feminist theorists like Carol Gilligan, Jean Baker Miller, Adrienne Rich, and others have argued that women are pressured to care more than are men, which is consistent with social cross-cultural meta-analyses (Phillips, 1995; Forssén, Carlstedt, and Mortberg, 2005; Hongwei, Fang, and Kolanowski, 2008). It is my hope that feminist researchers can avail themselves of this concept of moral othering, especially in view of its disabling qualities, so that our discussions of family obligations, women's obligations, and common morality can proceed even further.

\section{References}

AARP. (2008). IDOP 2008: Global perspectives on family caregiving.

Ali Jackson, N. (2007). Encyclopedia of domestic violence. Boca Raton, FL: CRC Press.

Aneshensel, C. S., Pearlin, L. I., Mullan, J. T., Zarit, S. H., \& Whitlatch, J. (1995). Profiles in caregiving. The unexpected career. San Diego, CA: Academic Press.

Annas, J. (1995). The morality of happiness. New York: Oxford University Press.

Bailey, C. (1997). Making waves and drawing lines: The politics of defining the vicissitudes of feminism. Hypatia, 12(3), 17-28.

Bauman, Z. (2004). Work, consumerism and the new poor. New York: McGrawHill International.

Bond, E. J. (2000). Bernard Gert's Moral System. Metaphilosophy, 31(4), 427445.

Callahan, D. (1985). What do children owe elderly parents? Hastings Report, 15(2), 32-37.

Daniels, N. (1988). Am I my parents' keeper? An essay on justice between the young and the old. New York: Oxford University Press.

Durmusoglu-Saltali, N. (2012). The relationship between abuse within the family and social skills of Turkish senior primary school children. Social Behavior and Personality: An International Journal, 40(4), 585. 
English, J. (1992). What do grown children owe their parents? In N. S. Jecker (Ed.), Aging And Ethics (pp. 147-154). Totawa, NJ: Humana Press.

Filonowicz, J. D. (2008). Fellow-feeling and the moral life. Cambridge, UK: Cambridge University Press.

Finch, J., \& Mason, J. (1990). Filial obligations and kin support for elderly people. Ageing \& Society, 10(2), 151-175.

Finley, N. J., Roberts, M. D., \& Banahan, B. F. (1988). Motivators and inhibitors of attitudes of filial obligation toward aging parents. The Gerontologist, 28(1), 73-78.

Forssén, A. S. K., \& Carlstedt, G. (2006). "It is heavenly to be alone!' A room of one's own as a health-promoting resource for women. Results from a qualitative study. Scandinavian Journal of Public Health, 34(2), 175-181.

Gert, B. (2004). Common morality: Deciding what to do. New York: Oxford University Press.

Guberman, N., Maheu, P., \& Maillé, C. (1992). Women as family caregivers: Why do they care? The Gerontologist, 32(5), 607-617.

Hendin, H., \& Hass, A. P. (1984). Wounds of war: The psychological aftermath of combat in Vietnam. New York: Basic Books.

Hodgetts, D., Pullman, D., \& Goto, A. (2003). Narrating the negative consequences of elder care and familial obligation in Atlantic Canada. Journal of Community \& Applied Social Psychology, 13(5), 378-390.

Hongwei, W., Fang, Y., \& Kolanowski, A. (2008). Caring for aging Chinese: Lessons learned from the United States. Shanghai Jiao Tong University School of Nursing, 19(2), 114-120.

Kendall-Tackett, K. A. (2005). Handbook Of women, stress, and trauma. New York: Psychology Press.

Lewis, H. B. (1971). Shame and guilt in neurosis. New York: International Universities Press.

Maguen, S., et al. (2010). The effects of PTSD on those returning from Iraq. Journal of Traumatic Stress, 23(1), 86-90. 
Marcoen, A. (2005). Parent care: The core component of intergenerational relationships in middle and late adulthood. European Journal of Ageing, 2(3), 208-212.

Narveson, J. (1987). On honouring our parents. The Southern Journal of Philosophy, 25(1), 65-78.

Nguyen, L. (2011). The ethics of trauma: Retraumatization in society's approach to the traumatized subject. International journal of Group Psychotherapy, 61(1), 27-47.

Noddings, N. (2003). Caring: A feminine approach to ethics \& moral education (2nd ed.). Berkeley, CA: University of California Press.

Opie, A. (n.d.). The instability of the caring body: Gender and caregivers of confused older people. Qualitative Health Research, 4, 31-50.

Opotow, S. (n.d.). Moral exclusion and injustice: An Introduction. Journal of Social Issues, 46, 1-20.

Pepin, J. I. (1992). Family caring and caring in nursing. Image: Journal of Nursing Scholarship, 24(2), 127-131.

Phillips, J. (2007). Care. Cambridge, UK: Polity Press.

Rickles-Jordan, A. (2007). Filial responsibility: A survey across time and oceans. Marquette Elder's Advisor, 9, 183.

Ryvicker, M. (2009). Preservation of self in the nursing home: Contradictory practices within two models of care. Journal of Aging Studies, 23(1), 1223.

Sherman, N. (n.d.). What good soldiers bear. America, The National Catholic Review, May 31, 2010.

Sherman, N. (2007). Stoic warriors: The ancient philosophy behind the military mind. New York: Oxford University Press.

Sherman, N. (2011). The untold war: Inside the hearts, minds, and souls of our soldiers. New York: W.W. Norton\& Company.

Stuifbergen, M. C., \& Van Delden, J. J. M. (2011). Filial obligations to elderly parents: a duty to care? Medicine, health care, and philosophy, 14(1), 6371. 
Williamson, G. M., \& Schulz, R. (1990). Relationship orientation, quality of prior relationship, and distress among caregivers of Alzheimer's patients. Psychology and Aging, 5(4), 502-509.

Wuest, J. (1998). Setting boundaries: A strategy for precarious ordering of women's caring demands. Research in Nursing \& Health, 21(1), 39-49.

Wuest, J., Hodgins, M. J., Malcolm, J., Merritt-Gray, M., \& Seaman, P. (2007). The effects of past relationship and obligation on health and health promotion in women caregivers of adult family members. ANS: Advances in Nursing Science, 30(3), 206-220.

Wuest, J., Malcolm, J., \& Merritt-Gray, M. (2010). Daughters' Obligation to Care in the Context of Past Abuse. Health Care for Women International, 31(12), 1047-1067.

Young, A. (1996). Suffering and the origins of traumatic memory. Daedalus, 125(1), 245-260.

Zhan, H. (n.d.). Aging, health care, and elder care: Perpetuation of gender inequalities in China. Health Care for Women International, 26, 693-712. 